\title{
Analysis of Physiologic Effect of Snowboard Deck in Snowboarders
}

\author{
Jinho Back ${ }^{1}$, Sun Hur $^{2 *}$ and Young-Mee Lee ${ }^{3}$ \\ ${ }^{1}$ Kangwon National University, Department of Leisure Sports, \\ ${ }^{2}$ Kangwon National University, Division of Sport Science \\ ${ }^{3}$ Kangwon National University, Department of Nursing \\ ${ }^{1}$ Gyodong 1,Samcheok City, Kangwondo Province ,Republic of Korea \\ ${ }^{2}$ Kangwon daehakGil, ChuncheonSi, Gangwondo Provice, Republic of Korea, \\ ${ }^{3}$ Hwangjo-Gil 346 Dogye-om, Gangwondo Province, Republic of Korea, \\ letssunny@kangwon.ac.kr
}

\begin{abstract}
The purpose of this study is to provide evaluation data to examine and verify the effectiveness of the materials through physiological comparison and analysis of the new prototype snowboard deck with the existing equipments. In order to achieve the purpose, blood lactate concentrations and energy metabolic variables were measured from the targeted snowboarders. Five male snowboarders (Slope-style) volunteered to participate in the experiment. The experiment was conducted in slope-style course of " $W$ " Ski Resort located in Gangwondo, Korea. One prototype deck and two existing deck were chosen for analysis. Each subject performed three runs with each " $B$ ", " $S$ " and " $Y$ " deck. Blood samples were collected twice from the finger-tip at rest and immediately after completing the run in order determine the lactate concentration. In order to analyze the energy metabolic variables i.e. heart rate (HR), oxygen uptake (VO2), metabolic equivalent (MET) and total energy consumption (TEE), portable wireless gas analyzer and Polar heart rate monitor was used at rest as well as during the run. The result obtained from the analysis showed increased blood lactate concentration as well as higher oxygen uptake (VO2) at the point of Lactate Threshold (LT) when performing runs by installing " $B$ " and " $Y$ " decks than " $S$ ". Furthermore with the increase in speed, depletion of energy sources as well as increased concentration of muscle fatigue substance also appeared in " $B$ " and " $Y$ " deck than " $S$ " where blood lactate concentration and oxygen uptake are indicators of mobilization capacity of lactic acid system during energy metabolism.
\end{abstract}

Keywords: Snowboard Deck, Blood Lactate Concentration, Energy Metabolic Variables

\section{Introduction}

With increasing economic condition, more and more people are being involved in winter sports. This has especially lured younger generation who seek for thrill and freedom through it [6]. Furthermore, its popularity has been added as the event takes a significant portion in 2018 Pyeonchang Winter Olympics with 10 gold medals out of total 93 Golds. Thus, making the sports much more competitive due to which countries around the world are investing in researches in different field such as Sports training, Sports biomechanics, Sports nutrition etc as well as in developing better equipments for athletes to get the best score. As Korea is

This research project was supported by the 2013 Sports Promotion Fund of Seoul Olympic Sports Promotion Foundation from Ministry of Culture, Sports and Tourism |

* Sun Hur 
hosting next 2018 Winter Olympics, domestic technology based products can contribute to develop the winter sports industry not only in Korea but also internationally further increasing our technological competitiveness [9]. As snowboarding is an outdoor sporting event, influences of external environment i.e., quality of snow; temperature etc., poses numerous limitation in analyzing physiological variables in actual sites [10]. In a previous study conducted [2] on six male athletes, degree of muscle glycogen was much more increased during exercise on snow than in the laboratory. Furthermore, rapid accumulation of lactic acid by fatigue on snow was also reported by [3]. Thus, these researches pointed out that performing experiment regarding the blood lactate concentration and energy metabolism in the field will be much more important on indicating the energy consumption than in laboratory condition. Based on these facts, the study aims to provide evaluation data for examining and verifying the effectiveness of the materials through physiological comparison and analysis of the new prototype snowboard deck with the existing equipments.

\section{Methods}

The experimental methods conducted in order to achieve the purpose of the study are presented as follows.

\subsection{Subjects}

Five male Slope-style snowboarders who are currently enrolled in the Korea Snowboard Association were chosen as subjects. Physical characteristics of the subjects are presented in Table 1.

Table 1. Physical Characteristics of the Subjects

\begin{tabular}{|c|c|c|c|}
\hline Height $(\mathbf{c m})$ & Weight $(\mathbf{k g})$ & Age(yrs) & Experience(yrs) \\
\hline $172.60 \pm 1.52$ & $63.40 \pm 4.72$ & $30.00 \pm 5.48$ & $5.80 \pm 2.49$ \\
\hline
\end{tabular}

\subsection{Experimental Design}

The test took place in the advanced Slope-style course at "W" Snowpark, Gangwondo Korea. The experimental slope was $420 \mathrm{~m}$ in length with average pitch of $20^{\circ}$ to maximum pitch of $30^{\circ}$ Figure 1.

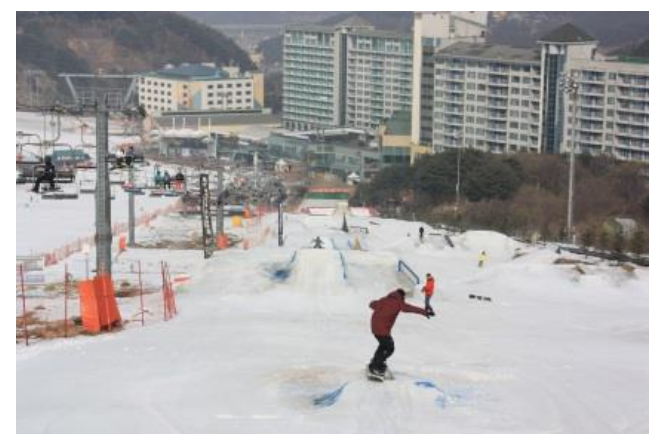

Figure 1. Experimental Slope

The weather was cloudy on the day of experiment with the temperature of $9.5^{\circ} \mathrm{C}$, humidity of $63 \%$, winds blowing from the northeasterly at the speed of $2.6 \mathrm{~m} / \mathrm{sec}$. All subjects complied 
with the process of a life ethics. Before the experiment, the purpose and procedures of the study were explained in detail to all subjects. In addition, subjects were fully explained regarding the processing of the data and the disadvantage to the study in case of absence. The participants who fully understood and who were willing to participate voluntarily signed the experiment consent form. Prior to the experiment, subjects were given sufficient amount of time to perform pre workout with stretching and warm-up. A twin tip freestyle snowboard deck constructed by "B" Co. was compared with the existing two products from "S" and "Y" company each. In order to control biasness to the study, Double Blind Test was performed on the subjects as well as the researchers involved in the study. Each subjects installed "B" "S" "Y" decks and performed three runs on the slope. Furthermore, the subjects were allowed 30 minutes to rest after completing each run.

\subsection{Data Analysis}

\subsubsection{Blood Lactate Concentration}

Before getting on the lift to the slope, subjects' blood samples at rest were collected at 7:30 am below the slope. The subjects were instructed to perform runs without stopping in the middle of the slope. In order to analyze the blood lactate concentration, second blood samples were collected with extreme care from each subject immediately after completing the run from the finger- tip using heparinized capillary tube without forming any bubbles. The collected samples were immediately packed in the tube and were analyzed by injecting into a lactate analyzer (Biosen C-line sport, EKF Diagnostic, Germany).

\subsubsection{Energy Metabolic Variables}

In order to analyze the heart rate (HR), oxygen uptake (VO2), metabolic equivalent (MET), total energy expenditure (TEE) in real time during experiments, subjects were equipped with Polar Heart Rate Monitor around the chest and a face mask attached with Portable Gas Analyzer (K4b2 CosMed, Italy). "K4b2" gas analyzer has been used in a various activities to measure exercise intensity and was proved to be suitable for the measurement of oxygen uptake and energy consumption [4]. Before conducting each run from top of the slope, subjects were given resting period on a chair for 3-5 minutes after which they performed the runs.

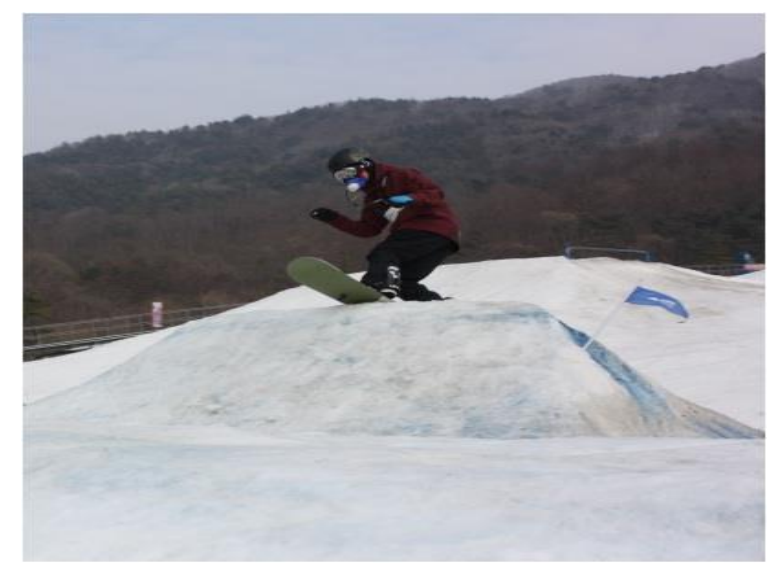

Figure 2. Gas Analyzer Experimental 


\section{Results}

\subsection{Blood Lactate Concentration}

The changes of the blood lactate concentration during the resting period and immediately after performing the turn are presented in Figure 3.

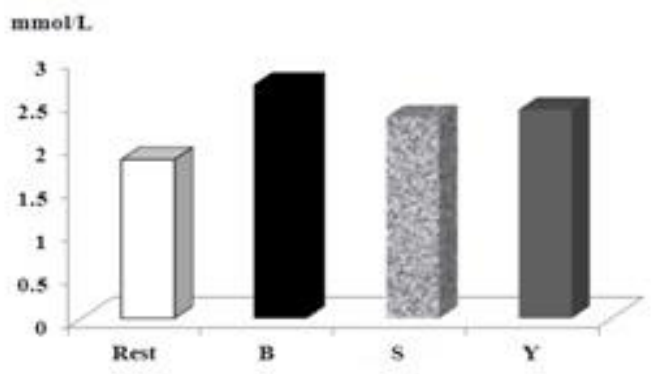

Figure 3. Changes of the Blood Lactate Concentration

Overall, right after performing the runs with "B", "S" and "Y" decks, increased blood lactate concentration was observed than comparing to at rest $(1.84 \pm .32 \mathrm{mmol} / \mathrm{L})$. In particular, blood lactate concentration when wearing "B" $(2.71 \pm .67 \mathrm{mmol} / \mathrm{L})$ and " $\mathrm{Y}$ " $(2.42 \pm 1.02 \mathrm{mmol} / \mathrm{L})$ decks was much higher in comparison to "S" $(2.33 \pm .59 \mathrm{mmol} / \mathrm{L})$ deck.

\subsection{Energy Metabolic Variables}

The changes of the metabolic variables in lactate threshold (LT) and maximal oxygen uptake (VO2max) during rest and after performing the runs are presented in Figure 4-7.

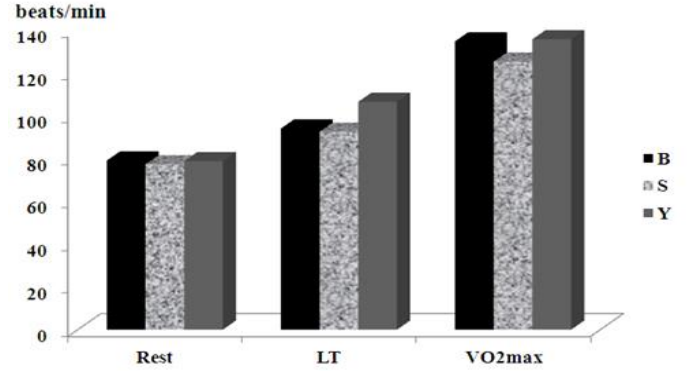

Figure 4. Changes of the HR

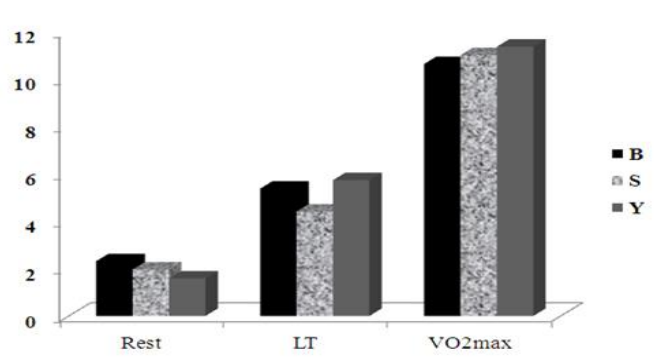

Figure 6. Changes of the MET

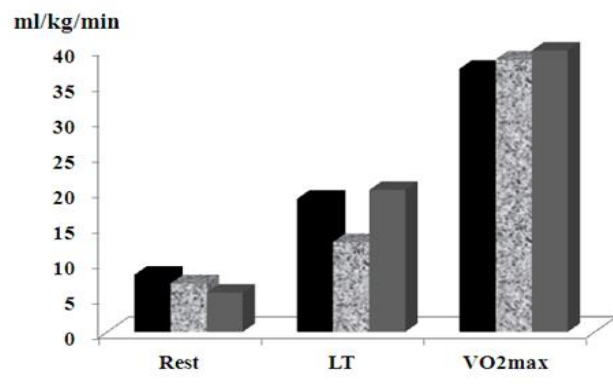

Figure 5. Changes of the $\mathrm{VO}_{2}$

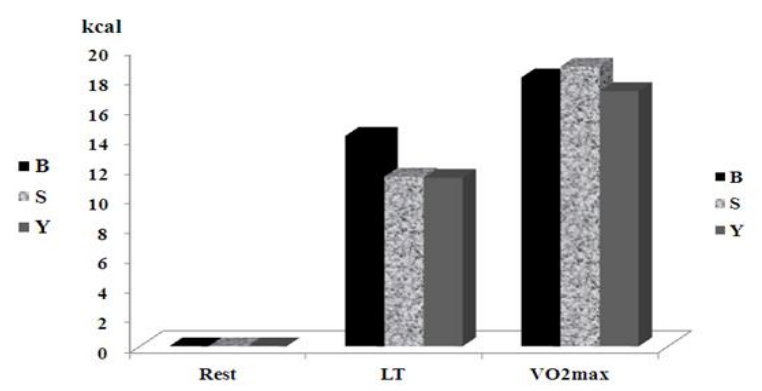

Figure 7. Changes of the TEE 
When installing "B", "S" and "Y" decks, heart rate (HR) was higher in the state of VO2max (134.75 $\pm 24.25 \mathrm{bpm}, 125.25 \pm 22.19 \mathrm{bpm}, 135.75 \pm 27.24 \mathrm{bpm})$ than at rest $(79.00 \pm 4.16 \mathrm{bpm}, 77.25 \pm 6.40 \mathrm{bpm}, 78.75 \pm 6.40 \mathrm{bpm})$ and at the state of lactate threshold $(94.00 \pm 6.27 \mathrm{bpm}, 92.50 \pm 3.00 \mathrm{bpm}, 106.50 \pm 17.29 \mathrm{bpm})$. VO2 and MET were much higher in the state of lactate threshold (LT) $(5.37 \pm .76,4.41 \pm 1.24,5.73 \pm 1.18)$ than at rest $(8.07 \pm 2.86 \mathrm{ml} / \mathrm{kg} / \mathrm{min}, \quad 6.84 \pm 2.56 \mathrm{ml} / \mathrm{kg} / \mathrm{min}, \quad 5.54 \pm 1.31 \mathrm{ml} / \mathrm{kg} / \mathrm{min}, \quad 2.31 \pm .81, \quad 1.96 \pm .73$, 1.58 \pm .38 ). Furthermore, VO2 and MET appeared highest at state of $\mathrm{VO} 2 \mathrm{max}$ $(37.20 \pm 4.76 \mathrm{ml} / \mathrm{kg} / \mathrm{min}, \quad 38.51 \pm 3.49 \mathrm{ml} / \mathrm{kg} / \mathrm{min}, \quad 39.78 \pm 3.24 \mathrm{ml} / \mathrm{kg} / \mathrm{min}, \quad 10.63 \pm 1.36$, $11.00 \pm 1.00,11.36 \pm .93$ ) than in the state of lactate threshold (LT). On the other hand, oxygen intake was increased when installing "B" $(18.80 \pm 2.64 \mathrm{ml} / \mathrm{kg} / \mathrm{min})$ and "Y" $(20.06 \pm 4.11 \mathrm{ml} / \mathrm{kg} / \mathrm{min})$ decks than performing runs on "S" $(12.70 \pm 3.68 \mathrm{ml} / \mathrm{kg} / \mathrm{min})$ deck in the state of the lactate threshold (LT). Also when installing "B" and "Y" decks, TEE was much higher in the state of lactate threshold (LT) $(14.12 \pm 7.11 \mathrm{kcal}, 11.30 \pm 2.74 \mathrm{kcal})$ and VO2max $(18.04 \pm 7.29 \mathrm{kcal}, 17.13 \pm 2.14 \mathrm{kcal})$ than at rest. In case of "S" deck, it was much higher in the state of lactate threshold (LT) $(11.39 \pm 3.22 \mathrm{kcal})$ than at rest and it was much higher in the state of $\mathrm{VO} 2 \max (18.77 \pm 7.50 \mathrm{kcal})$ than in the state of lactate threshold (LT).

\section{Discussion and Conclusion}

It is considered that this study has provided significant physiological evidence data to improve snowboard deck products though examining and verifying the effectiveness of "B", "S" and "Y" deck by measuring the blood lactate concentration and the changes of the energy metabolism variables of male snowboarders Different researches [7, 8] have mentioned about "Lactic acid" a fatigue material which evaluates the physical intensity or the load as well as physiological changes when performing activity, is used as a reference value for improving the performance of athletes, analyzing the effectiveness of training, a degree for excessive training as well as to control the exercise intensity [5]. According to the results obtained from the study, increased blood lactate concentration was observed after performing runs than at rest on all decks i.e., "B", "S" and "Y". Particularly, higher blood concentration was observed in " $B$ " and "Y" decks than "S". It is considered that these results are indicators that represent the mobilization capabilities of the lactic acid system during energy metabolic process which appeared due to depletion of energy sources as well as due to the increase in fatigue substance concentrations in the peripheral muscles through the performed activity. When snowboarding, high lactate levels are caused in part by occlusion during continuous isometric contractions which results in restriction of blood flow of vastus lateralis [11]. In addition, according to the individual fitness level, intensity of muscle contraction and the type of muscle contraction, the angle of the turn or even the radius of the action etc., drastically affects stimulates physiological response due to which stresses the muscles [1]. In order to analyze the intensity of exercise in snowboarding, better insight in the concentration of lactate acid can represent complex physiological functions than only relying on heart rate data that is mainly affected by the stimulation around the heart due which may lead to misinterpretation of the data. Lactate threshold (LT) is a useful indicator for the evaluation of athletic ability. According to the result obtained from this study, the oxygen uptake when installing " $B$ " and " $Y$ " decks were much higher than when installing "S" deck at the state of lactate threshold. On the other hand, the MET of snowboard athletes are reported to be 7-11 [3]. The results obtained from our experiment regarding the MET of the subjects were 10-11 level at the state of VO2max proves the intensity of the experiment performed.

As environmental condition such as temperatures, snow conditions, the change in areas etc., influence deeply on the physiological responses of the exercise intensity. The study 
conducted can be a significant reference data to analyze the physiological effects targeting snowboarders in laboratory conditions too.

\section{References}

[1] R. E. Andersen and D. L. Montgomery, "Physiology of alpine skiing", Sports Medicine, (1988), pp. $210-221$.

[2] E. Blomstrand and B. Essén-Gustavsson, "Influence of reduced muscle temperature on metabolism type I and type II human muscle fibers during intensive exercise”, Acta Physiologica Scandinavica, (1987), pp. 569-574.

[3] J. W. Castellani and A. J. Young, "Health and performance challenges during sports training and competition in cold weather", British of Journal Sports Medicine, (2012), pp. 788-791.

[4] Y. S. Koh and I. G. Jeong, "Portable metabolic measurement system accurately measure metabolic variables during sub-and maximal exercise", Journal of Sports and Leisure Studies, (2007), pp. 833-842.

[5] C. Juel, C. Klarskov, J. J. Nielsen, P. Krustrup, M. Mohr and J. Bangsbo, "Effect of high-intensity intermittent training on lactate and $\mathrm{H}$ iron release from human skeletal muscle", American Journal of Physiology, Endocrinology and Metabolism, (2004), pp. 245-251.

[6] J. Young-Hak, "The Effects Of Acute Stretching And Kinesio-Taping In Isokinetic Muscle Strength In Snowboarders", Postgraduate thesis, Graduate School of Korea National University of Education, Korea, (2009).

[7] M. Langran and S. Selvaraj, "Increased injury risk among first-day skiers, snowboarders, and skiboarders", American Journal of Sports Medicine, (2004), pp. 96-103.

[8] M. C. Meyers and C. M. Laurent Jr., R. W. Higgins and W. A. Skelly, "Downhill ski injuries in children and adolescents", Sports Medicine, (2007), pp. 485-499.

[9] H. Y. Park, T. S. Cho and S. H. Mun, "The effect on satisfaction and buying behavior according to product attribute of snowboard deck", Journal of Sports and Leisure Studies, (2012), pp. 63-75.

[10] C. M. Suh, "Effect of ski and snow-board sport on beta-endorphin and norepinephrine secretion", The Korean Journal of Sport, (2012), pp. 225-237.

[11] L. Szmedra, J. Im, S. Nioka, B. Chance and K. W. Rundell, "Hemoglobin/myoglobin oxygen desaturation during alpine skiing”, Medicine and Science in Sports and Exercise, (2001), pp. 232-236.

\section{Authors}

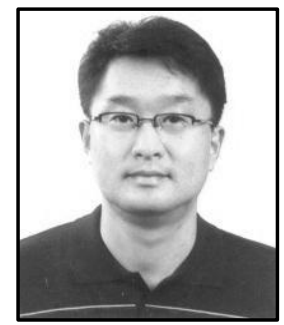

Jin ho Back is a professor at Department of Leisure Sports, Kangwon National University Samcheok campus. He received his Ph.D. degree from Sungkyunkwan University, Korea in 1997. He was a senior researcher at Korea institute of Sports science from 1997 to 2008. Currently, He is an executive director as well as editor of Korean Society of Sports Biomechanics (KSSB). His research interests include Sports Biomechanics and Motion Analysis.

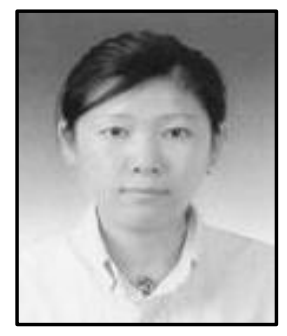

Sun Hur is a researcher at Division of Sports Science, Kangwon National University. She received her Ph.D. degree from Kangwon National University, Korea in 2009. She was a researcher professor at Kangwon National University from 2010 to 2013. Her research interests include Exercise Physiology, Exercise Prescription and Training Methodology.

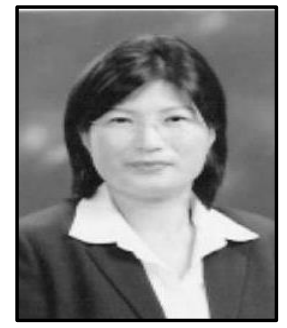

Young-Mee Lee is a professor Kangwon National University. She received her Ph.D degree from Catholic University, Korea in 2003. Her research interests include disaster nursing and emergency care. 